\title{
Investigation Die Profile Effect on Nosing Process Using Finite Element Method
}

\author{
Asst. Luct.M.Sc Eng. Darya Sarwar Mohammed Salih \\ Production Eng.and Metallurgy Department \\ Sulaimani Technical college \\ Sulaimanyah-Iraq \\ Asst. Prof. Dr. Eng. Azal Rifaat Ismail \\ Dept. of Production Engineering and Metallurgy \\ University of Technology \\ Baghdad-Iraq
}

Received: December 8, 2011

Accepted: December 22, 2011

doi:10.5539/mas.v5n2p212

\begin{abstract}
The study aims to use the finite element analysis in nosing process. After making a preliminary study on the shell nosing parameters, two conical die with semi-die angles $\left(10^{\circ}, 20^{\circ}\right)$ have been designed and simulated using the (ANSYS 5.4) software package. The process has been carried out using pure Aluminum shells of $(1.5,3,4.5)$ $\mathrm{mm}$ thickness under conditions of cold and hot nosing process at $\left(400 \mathrm{C}^{\circ}\right)$, specimens having a diameter $(50)$ $\mathrm{mm}$ and length $(100) \mathrm{mm}$. The nosing process involves implementing two dies $\left(10^{\circ}, 20^{\circ}\right)$ using pure Aluminum shells of $(3,4) \mathrm{mm}$ thickness with several speeds and with a mixture of oil and graphite as lubrication, a good agreement is obtained between the experimental work and the simulation. It is noted that the best die is conical die with $\left(10^{\circ}\right)$ die semi angle.
\end{abstract}

Keywords: Nosing, FEM, Die profile

\section{Introduction}

Nosing is a hot or cold forming process in which the open end of a shell or tubular component is closed by axial pressing with a shaped die as shown in Fig. (1).

The metal flow is complex and sensitive to the frictional constraint at the die work-piece interface. In general, wall thickness increases, and the shell shrinks in length after the operation (depending upon friction) (Ming C. T.g, May H. and Shiro K. 1982). The shape of the outer surface of the shell follows the nosing die profile while the inner surface is not supported during the nosing process. In hot nosing (for large diameter shells $=155 \mathrm{~mm}$ and above), the metal flow depends upon friction, temperature of the work-piece, and speed of the operation (G.D. Lahoti and T. Altan. 1978).

The hot nosing of large shells is done by heating the end portion of the tube to be formed by tubular wound induction coils, and then the shell is nosed by forcing it into a suitably shaped die. Determination of these temperatures distributions along the length of the shell wall is important and necessary to predict accurately the flow of metal and the nosing load in the hot nosing. In fact, the temperature distribution is rather critical and much effort has been concentrated on the preheating conditions. If the heating is gradual and slow, the unheated portion of the tube gains heat. Therefore, preheating is done at a rapid rate so that the high temperature does not travel back to that part of the shell which should remain relatively cold (Ming C. T. and Shiro K. 1982)( S.M.Hwang and Shiro K. 1987)( Ming C. T. and Shiro K. 1982)( Ken I. M. and Hisashi N. 1984).

The need for investigation of simulations using finite element method which has the ability to evaluate the required force in nosing process has become very important and necessary to reduce time and cost. The main objective of this work is to establish the principles of nosing process through different die profiles. Different parameters which affect the nosing load were determined by studying the effect of die profile on the nosing load to find the optimum die profile that can be used with lowest stresses and minimum friction forces.

\section{Theoretical considerations:}

In a number of forming processes a thin walled metal shell of rotational symmetry is pulled or pushed by an axial force through a die opening, and undergoes a reduction in diameter, reducing processes of the pushing type which may be necking, tapering, nosing, and closing forms. Of these, only the necking is a steady-state flow process, while the others processes are unsteady-state processes.

The relation between forming stress ( $\mathrm{p} / \mathrm{Ao}$ ) and nosing ratio $\mathrm{R}$. as shown in figure (2).

$$
R=\left(\frac{r_{o}-r_{n}}{r_{o}}\right)
$$


The relation between forming stress $(\mathrm{P} / \mathrm{Ao})$ and the proportional displacement of the punch $(\mathrm{S} / \mathrm{ro})$ as shown in figure (3).

The equilibrium of forces in the direction of $\left(\sigma_{2}\right)$ will be

$$
\sigma_{2}\left(\frac{r-d \theta d r}{\sin \alpha}\right)-2 \sigma_{3} \cdot \cos \left(\alpha+\frac{\beta}{2}\right) \frac{\sin d \theta}{2}\left(\frac{t \cdot d r}{\sin \alpha}\right)=0
$$

Since the angles $(d \theta, \beta)$ are small and the summation of small quantities is too low, therefore, the equilibrium will be:

$$
\sigma_{2} \cdot r=\sigma_{3} \cos \alpha . t \quad \sigma_{2}=\left(\frac{t}{r} \cdot \cos \alpha\right) \sigma_{3} .
$$

The equation (2) shows that $\left(\sigma_{2}\right)$ is much less than $\left(\sigma_{3}\right)$ for thin wall specimen .and the equilibrium of forces in $\left(\sigma_{1}\right)$ direction is:

$$
\begin{aligned}
& \left(\sigma_{1}+d \sigma_{1}\right)(r+d r)(t+d t) d \theta-\sigma_{1} \cdot t \cdot r \cdot d \theta-. \sigma_{3}\left(\frac{t d r}{\sin \alpha}\right) d \theta \cdot \sin \alpha- \\
& \mu \sigma_{2}\left(\frac{r \cdot d \theta \cdot d r}{\sin \alpha}\right)=0
\end{aligned}
$$

Dividing the equation by $(d r . d \theta)$ gives:

$$
\begin{aligned}
& \frac{\left(\sigma_{1}+d \sigma_{1}\right)(r+d r)(t+d t)-\sigma_{1} . t . r}{d r}-\sigma_{3} \cdot t-\mu \sigma_{2} \frac{r}{\sin \alpha}=0 \\
& \frac{\sigma_{1} \cdot r . t+d \sigma \cdot r . t+d \sigma_{1} \cdot r \cdot d t+d \sigma_{1} \cdot d r . t+\sigma_{1} \cdot r \cdot d t+\sigma_{1} \cdot t \cdot d r}{d r} \\
& -\sigma_{3} . t .-\mu \sigma_{2} \frac{r}{\sin \alpha}=0
\end{aligned}
$$

Ignoring small quantities:

$$
d\left(\frac{\sigma_{1} \cdot r . t}{d r}\right)-\sigma_{3} . t-\mu \sigma_{2} \frac{r}{\sin \alpha}=0 .
$$

From eqn. (2) substitute $\left(\sigma_{t}\right)$ in eqn.( 3 ):

$$
\begin{aligned}
& d\left(\frac{\sigma_{1} \cdot t \cdot r}{d r}\right)-. \sigma_{3} \cdot t-\sigma_{3}\left(\frac{t}{r} \cos \alpha\right) \cdot \mu \frac{r}{\sin \alpha}=0 \\
& d\left(\frac{\sigma_{1} . t . r}{d r}\right)-\sigma_{3} . t(1+\mu \cot \alpha)=0 .
\end{aligned}
$$

Moreover, assuming the wall thickness is constant then the equation becomes:

$d\left(\frac{\sigma_{1} \cdot r}{d r}\right)-\sigma_{3}(1+\mu \cot \alpha)=0$

Using von- Mises yield criterion and assuming that $\left(\left|\sigma_{l}\right|<\left|\sigma_{3}\right|\right)$ and within this range a specific value for $(\bar{Y})$

$$
\sigma_{3}=\bar{Y}=1.1 Y_{o}
$$

Substituting eqn.( 6 ) in eqn. (5):

$$
d\left(\frac{\sigma_{1} \cdot r}{d r}\right)-1.1 Y_{o}(1+\mu \cot \alpha)=0
$$

Integrating eq. (7) gives

$$
\sigma_{1}=1.1 Y_{o}(1+\mu \cot \alpha)+\frac{c}{r}
$$

Where $(c)$ is integration constant which depends on the boundary condition of the problem where the longitudinal stress $\left(\sigma_{l}\right)$ is zero at the nosing end when $\left(r=r_{n}\right)$ then the value of $(c)$ becomes:

$$
c=-1.1 Y_{o}(1+\mu \cot \alpha) r_{n}
$$

Substitute the value of $(c)$ in eqn. (8), the final equation of the longitudinal stress becomes: 
$\sigma_{1}=1.1 Y_{o}(1+\mu \cot \alpha)\left(1-\frac{r_{n}}{r}\right)$

Maximum longitudinal stress will be according to eqn. (10), when $\left(r=r_{o}\right)$ at the entry of the die where:

$$
\sigma_{1_{\max }}=1.1 Y_{o}(1+\mu \cot \alpha)\left(1-\frac{r_{n}}{r}\right) \text {. }
$$

The required nosing load $(p)$ depending on the resultant equilibrium of $\left(\sigma_{I \max }\right)$ with the load $(p)$, as illustrated in fig. (2-3), will be:

$p=\sigma_{1 \text { max. }}\left(A_{o}\right) \cos \alpha$

Where, $A_{o}$ is the original cross sectional area of the specimen. The relation between forming stress and nosing ratio will be obtained by substituting eqn (1) in eqn(11)

Then applying eq. (12) gives the final relation between forming stress $\left(p / A_{o}\right)$ and nosing ratio $(R)$ as:

$$
\frac{P}{A_{o}}=1.1 Y_{o}(1+\mu \cot \alpha)(\cos \alpha) \cdot R
$$

\section{Experimental work}

A universal testing machine (shimadzu type) $250 \mathrm{KN}$ capacity was used as shown in Fig. pure Aluminum with properties shown below:

$\begin{array}{ll}\text { - } & \text { Modulus of elasticity } \\ \text { - } & \text { Tangent modulus } \\ \text { - } & \text { Weight density } \\ \text { - } & \text { Poisson's ratio } \\ \text { - } & \text { Coefficient of thermal expansion (APLX) } \\ \text { - } & \text { Thermal conductivity } \\ \text { - } & \text { Specific heat }\end{array}$

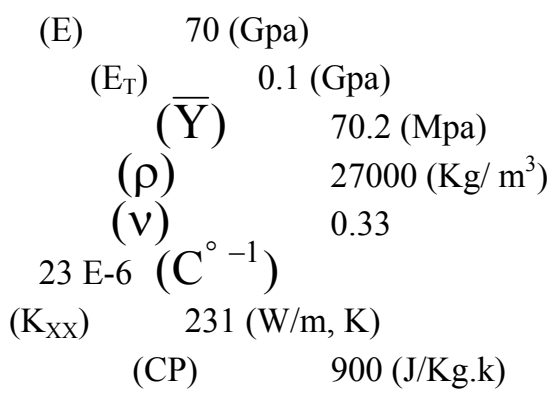

\section{Results and Discussion}

Figure (6) represents the load-displacement relationship for several thicknesses $(1.5,3.0$, and 4.5$) \mathrm{mm}$, different die angles $(10,20)$ and ram speed equal to $300 \mathrm{~mm} / \mathrm{min}$. It is shown from the figures that the load increases with increasing shell wall thickness, which does not match (Al-Rubai'i survey) (A.K. Cruden and J.F. Thomson. 1972) who showed that the thickness has a slight effect on the nosing load.

It is noted that the load decreases on the last stages on the load-displacement curves for thickness $(1.5,3) \mathrm{mm}$ in the conical die semi-angle $=20^{\circ}$ due to the ax symmetric buckling modes, which appear because of the high contact between the nosing die and shell. In the last stages of nosing process (for large die semi-angles) the shell penetration rate inside the load increases, in (4.5) $\mathrm{mm}$ thickness, due to the decrease of buckling. The buckling appears with increasing die semi-angle which matches (T.T.Q. Al-Qahwaji survey) (Zhu-J. 1997). It is also obvious that the load increases with increasing die semi-angle, because the region of the shell near the die inlet is subjected to bending thus for large die semi-angles, the nosing load is strongly affected by the bending deformation, increasing die semi-angle increases the reduction area and the die friction load, therefore a higher nosing load is required which matches with (S.Y. Al-Qasab survey) (Endo-J, Murota-T, Kato-K, Hatada-N. 1987). The increment of the load appears at the early stages of the nosing process, because the shell changes most markedly near the die inlet where large deformation occurred and the bending deformation is localized at this portion. (Ken I. M. and Hisashi N. 1984).

Figure (7) shows the results of simulation for conical die semi-angle $=20^{\circ}$ with shell thickness $(1.5,3,4.5) \mathrm{mm}$ and die semi-angle $=10$ with thickness $\mathrm{t}=1.5 \mathrm{~mm}$ with ram speed $=300 \mathrm{~mm} / \mathrm{min}$. The ax-symmetric buckling appears for large die semi-angles and is reduced with the increasing thickness, the effective stress distribution on the shell wall. The die profile directly influences material flow, and therefore it affects the distribution of the effective stress in the deformation zone. The effective stress distribution has the highest values in the nose tip region where large deformation occurred. For die semi-angle $=20^{\circ}$, the effective stress distribution in the shell wall outside the die increases in the ax symmetric buckling zones.

Figure (8) represents the load-displacement relationships for both hot (at $400 \mathrm{C}^{\circ}$ ) and cold nosing by simulation, using the same parameters as in fig. -1- it is obvious that for hot condition the load will be less than the condition in cold nosing, and figure (9) shows the results of simulation of hot nosing (at the end portion of the shell wall) for conical die semi-angle $=10^{\circ}$, thickness $=1.5 \mathrm{~mm}$ and ram speed $=300 \mathrm{~mm} / \mathrm{min}$, the load decreases in the hot nosing due to decrease in the yield point and strain hardening of the shell. The hot process is useful to reduce the load required for the nosing process and the reducing is about $(23 \%)$. 
Figure (10) represents the comparison in load-displacement relationship between the experimental work and the simulation. The simulation prediction are somewhat lower than the experimental values, but in general there is a good agreement between the results of simulation and of experimental work, this is because the lubricant was squeezed out as the shell penetrated deeper into the die and that will change the friction amount between the shell and the nosing die, the load will be changes.

Figure (11) shows the thickness distribution for both the experimental work and simulation there is a good agreement between experimental work and simulation, for the experimental work, the shells were cut along a diametric plane and the cross-sections were marked with lines and the thickness of the nosed specimens along these lines were then measured and compared with the results of simulation, thicknesses increased significantly throughout the nosed portion, with the largest increase at the leading edge of the nose, because the outer surface of the part follows the die profile (friction between the die and the shell) while the inner surface is not supported. Figure (12) shows the shells for both simulation and experimental (after cutting along the diametric plane and the marked lines). It is obvious that there is no buckling in the shell wall (even for the conical die semi-angle $=20^{\circ}$ ) because the penetration of the shell inside the die hole is lower $\{$ displacement $=(25) \mathrm{mm}\}$.

\section{Conclusions}

1) The optimum die angle for the conical dies is $\left(10^{\circ}\right)$

2) The load decreases with decreasing shell wall thickness but on the other hand, for large die semi-angle the buckling appears with decreasing shell wall thickness.

\section{References}

A. Fatnassi, Y. Tomita and A. Shindo. (1985). Non-axisymmetric buckling behavior of elastic-plastic circular tubes subjected to a nosing operation. Int, journal of mechanical Soc. Vol. 27, P: 643-651.

A.K. Cruden and J.F. Thomson. (1972). The end closure of backward extruded cans. Nel report No.511, Glasgow.

Azal R. Ismail. (2002). Numerical simulation of 3-D regular polygonal sections in forward extrusion by elastic-plastic finite element method. Ph.D. Thesis, production Eng. Department, Univ. of technology.

Basim M.A. Clor and Majid H. Ali. (1993). Experimental investigation of nosing with circular curved dies. Journal of Engineering and Technology, vol.12, No.7, P: 69-76.

Basim M.A. Clor and Safeen Y.I. Al-Qassab. (1993). Effect of work hardening characteristics on conical nosing. Journal of Engineering and Technology, vol.11, No.9, P: 9-18.

Basim M.A. Clor. (1992). The yield condition for conical nosing. Journal of Engineering and Technology, vol.11, No,6. p: 97-115.

Dr. Basim M.A. Clor and Salam A. Al-Saffar. (1992). Effect of frictional conduction on conical nosing. Journal of Engineering and Technology, vol.11, No,5. p: 9-19.

Dr. Basim M.A. Clor and Tahseen T.O. Al-Qahwaji. (1992). Experimented study of conical nosing. Journal of Engineering and Technology, vol.11, No,7. p: 50-61.

Endo-J, Murota-T, Kato-K, Hatada-N. (1987). Theoretical prediction on non-axisymmetric buckling in tube nosing. J. advanced technology of plasticity, P:1347-1353.

G.D. Lahoti and T. Altan. (1978). Analysis of metal flow in nosing of tubular products. Proc., 6th Namrc. P: 151-157.

Ken I. M. and Hisashi N. (1984). Nosing of thin-walled tubes by circular curved dies. Journal of mechanical working technology, Vol.10, P: 287-298.

Kwan-C-T, Fang-C-H, Chiu-C-J, Chen-S-W, Wen-H-W. (2004). An analysis of the nosing process of metal tubes. International journal of advanced manufacturing technology, P:190-196.

Manohar S. (1964). A linearized theory of nosing of shells. Journal of applied mechanics, vol.31, P: 535-539.

Ming C. T. and Shiro K. (1982). An investigation of the shell nosing process by the finite-element method. Part

2: nosing at elevated temperature [hot nosing]. Journal of engineering for industry, Vol.104, P: $312-318$.

Ming C. T. and Shiro K. (1982). An investigation of the shell nosing process by the finite-element method. Part 1: nosing at room temperature [cold nosing]. Journal of engineering for industry, Vol. 104, P: 305-311.

Ming C. T.g, May H. and Shiro K. (1982). Analysis of shell nosing-process mechanics and preform design. Int.J.Mech. Tool Des.Res. Vol.22, No.4, P: 293-307.

P.Karpp, Paul G. and Fee M.L. (1977). Mechanics of hot nosing of shells. Proc., 5th NAMRC, P: 179-182.

S.M.Hwang and Shiro K. (1987). Preform design in shell nosing at elevated temperatures. Int.J.Mech. Tools Manufacture. Vol.27, No.1. P: 1-14.

Saeed Moaveni. (1999). Finite element analysis, theory and application with Ansys.

Tang-J-P, Oh-S-I, Lee-F-M. (1983). A computerized process design system for manufacturing shells and other cup-shaped components. ASM metals congress. 
Zhu-J. (1997). A new approach to preform design in shell nosing. Journal of material processing technology). P:640-644.

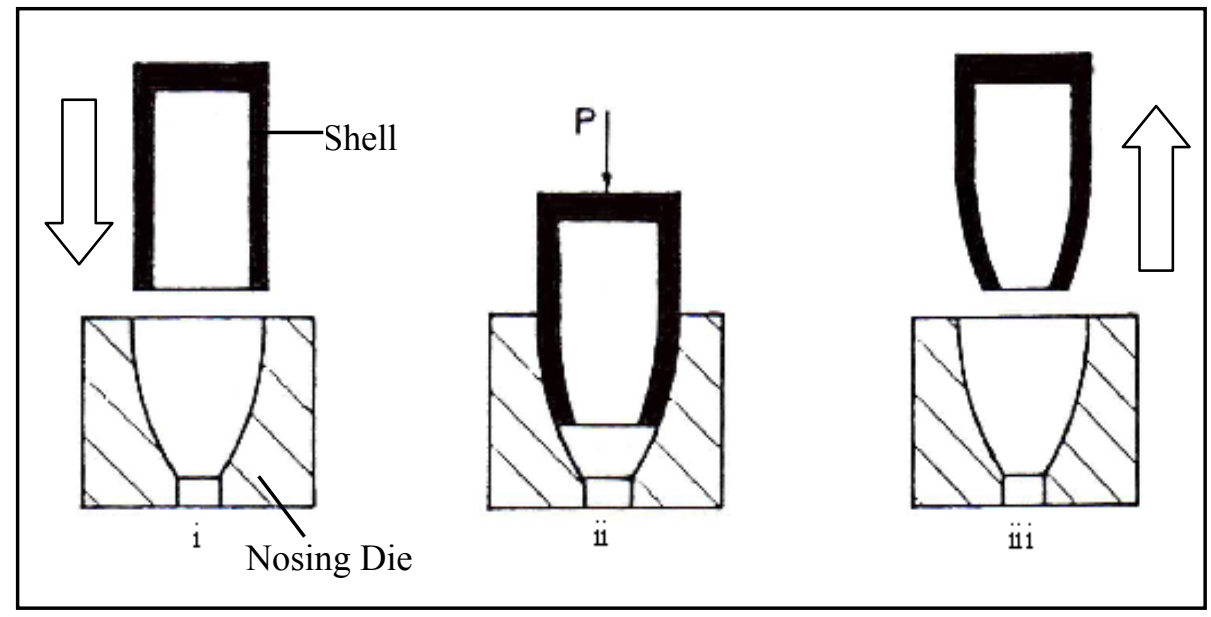

Figure 1. Nosing die

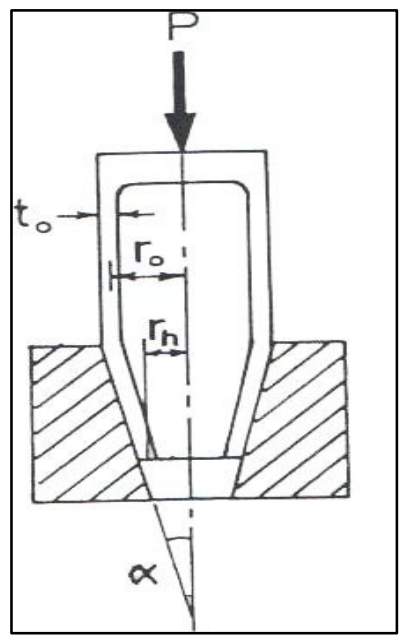

Figure 2. conical nosing

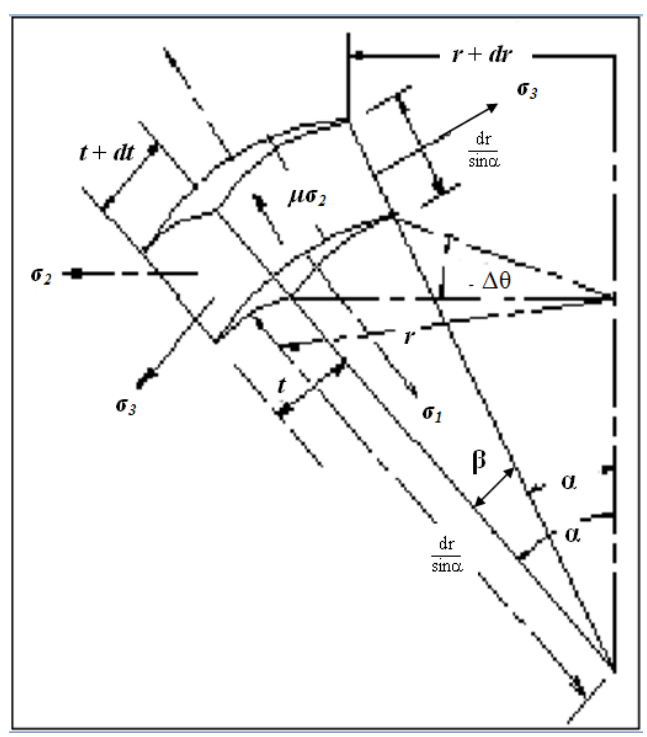

Figure 3. differential element at the shell wall 


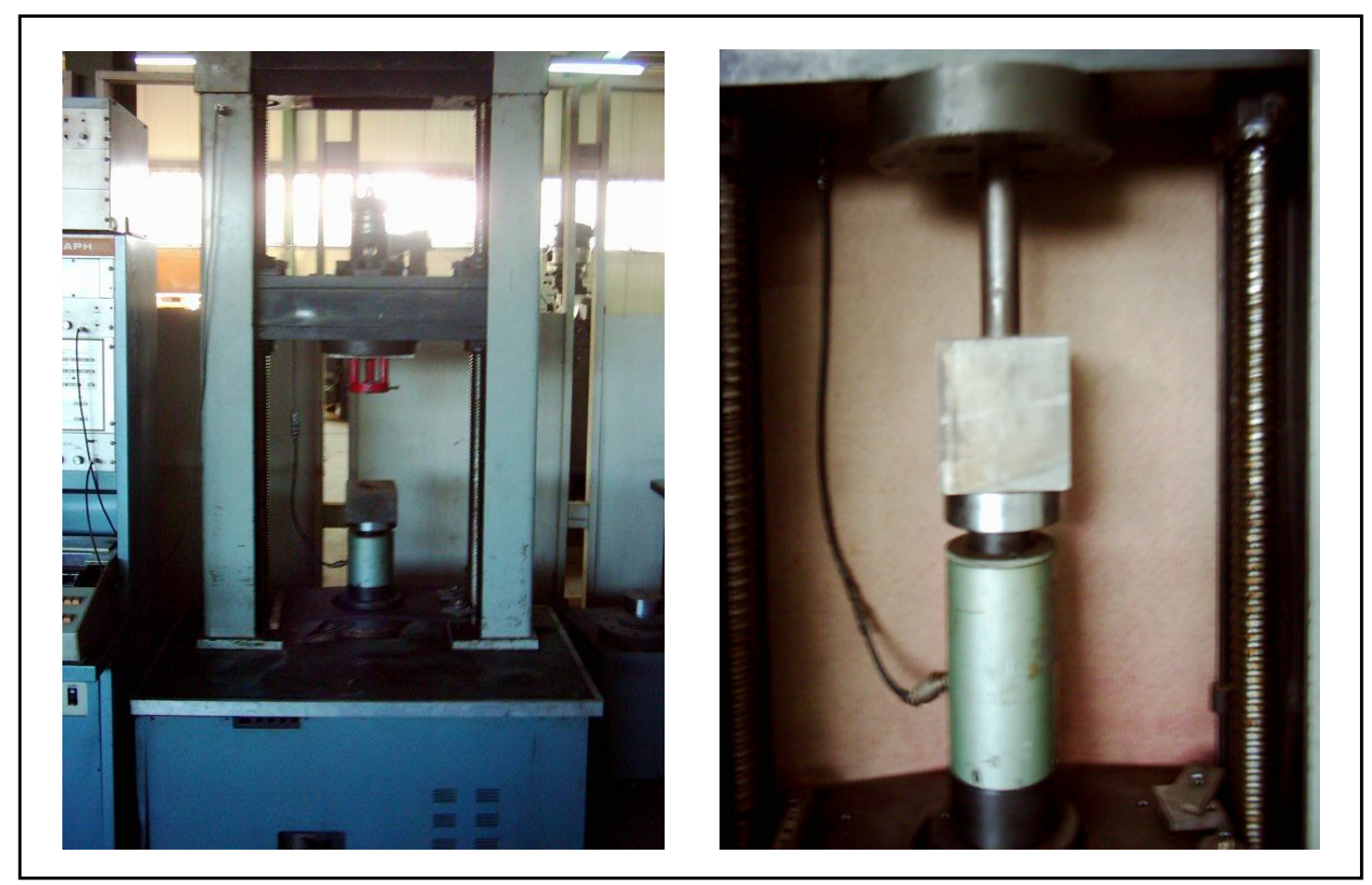

Figure 4. the Universal Testing Machine Photographs

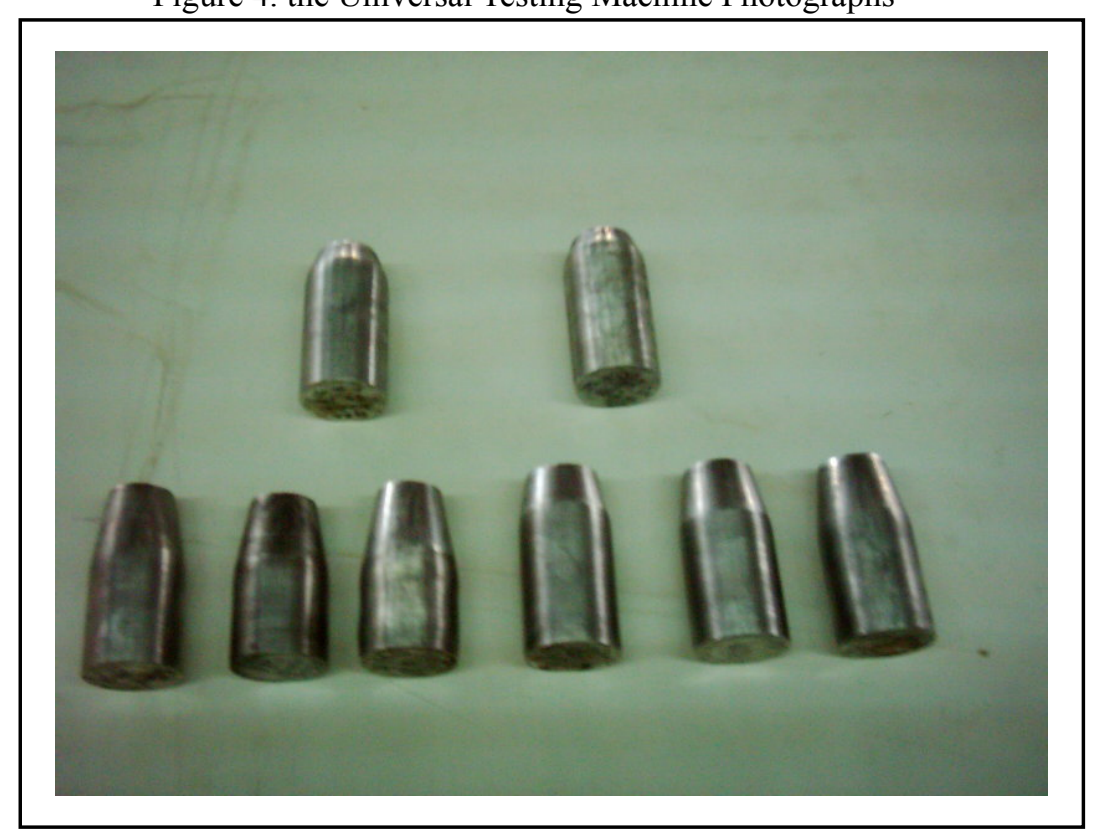

Figure 5. Photograph of Shells after cold Nosing Process 


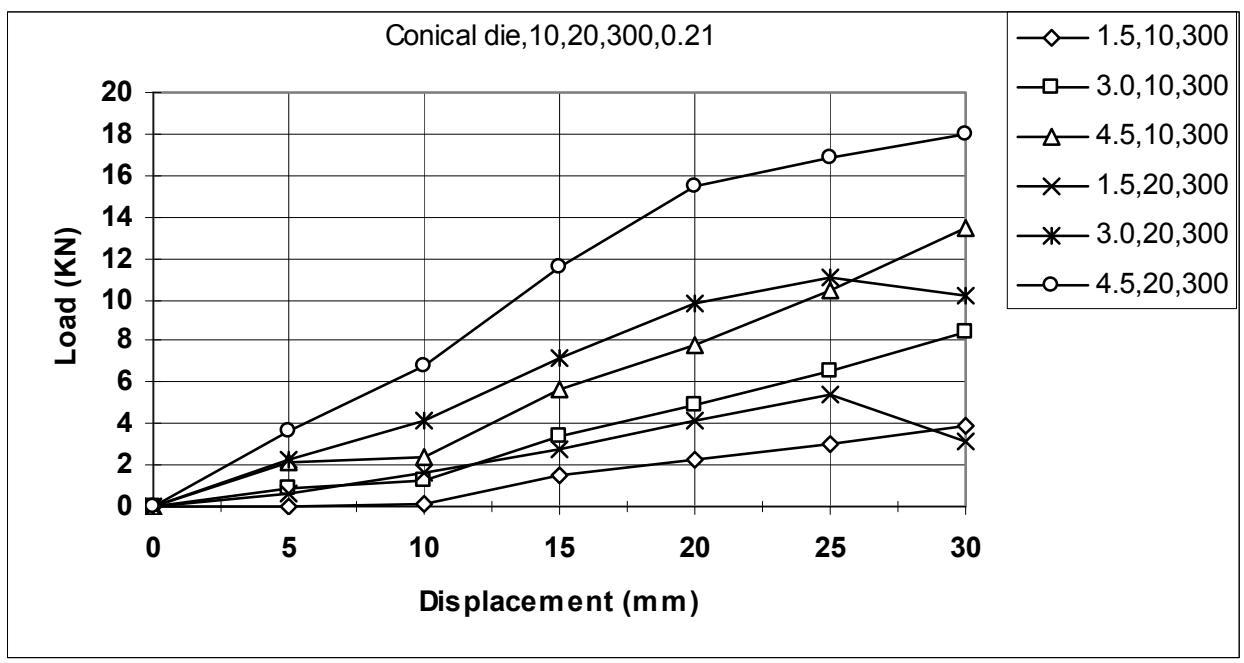

Figure 6. the load-displacement for shell nosing simulation

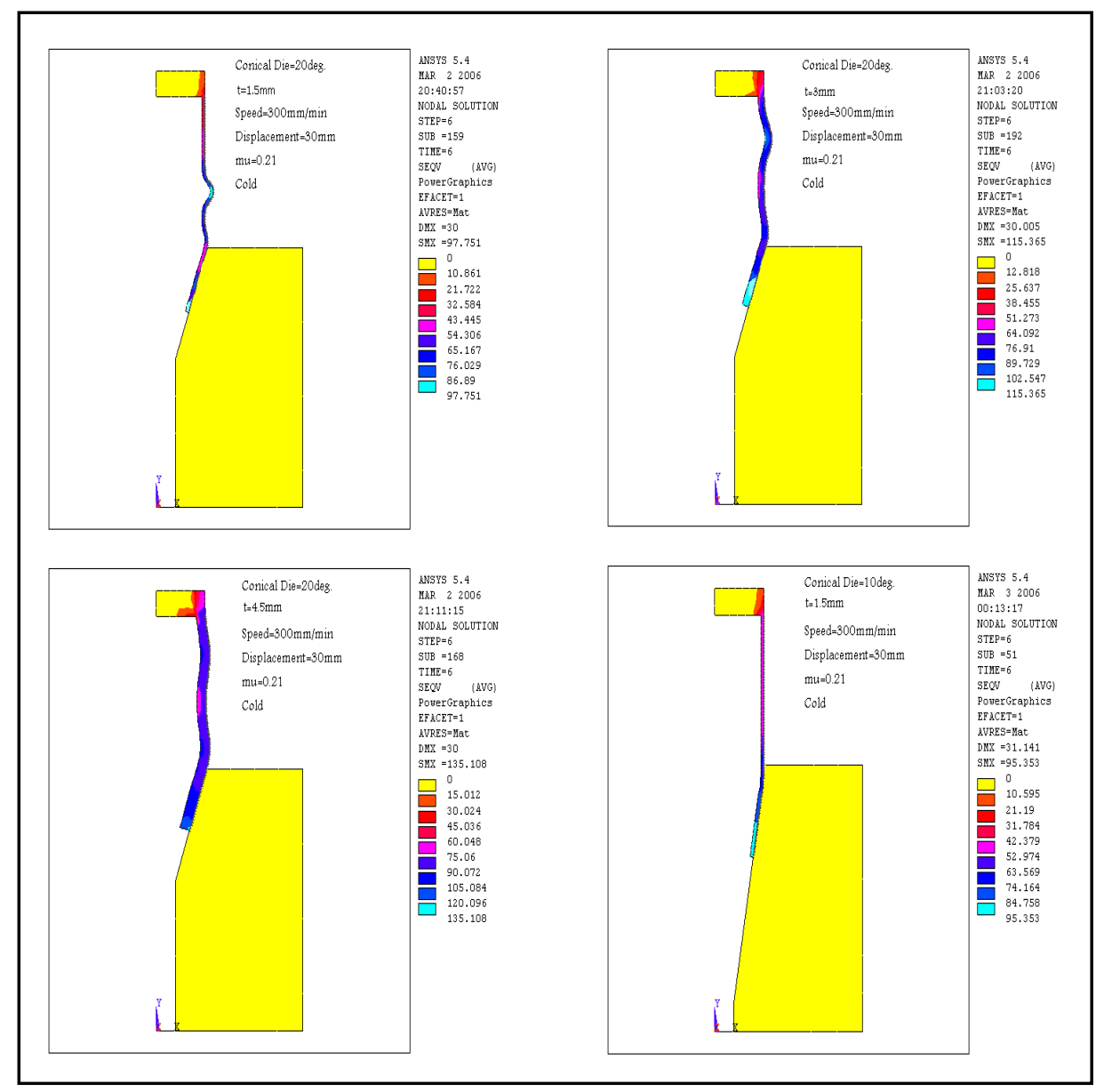

Figure 7. simulation for conical die and the equivalent stress distribution on the shell wall 


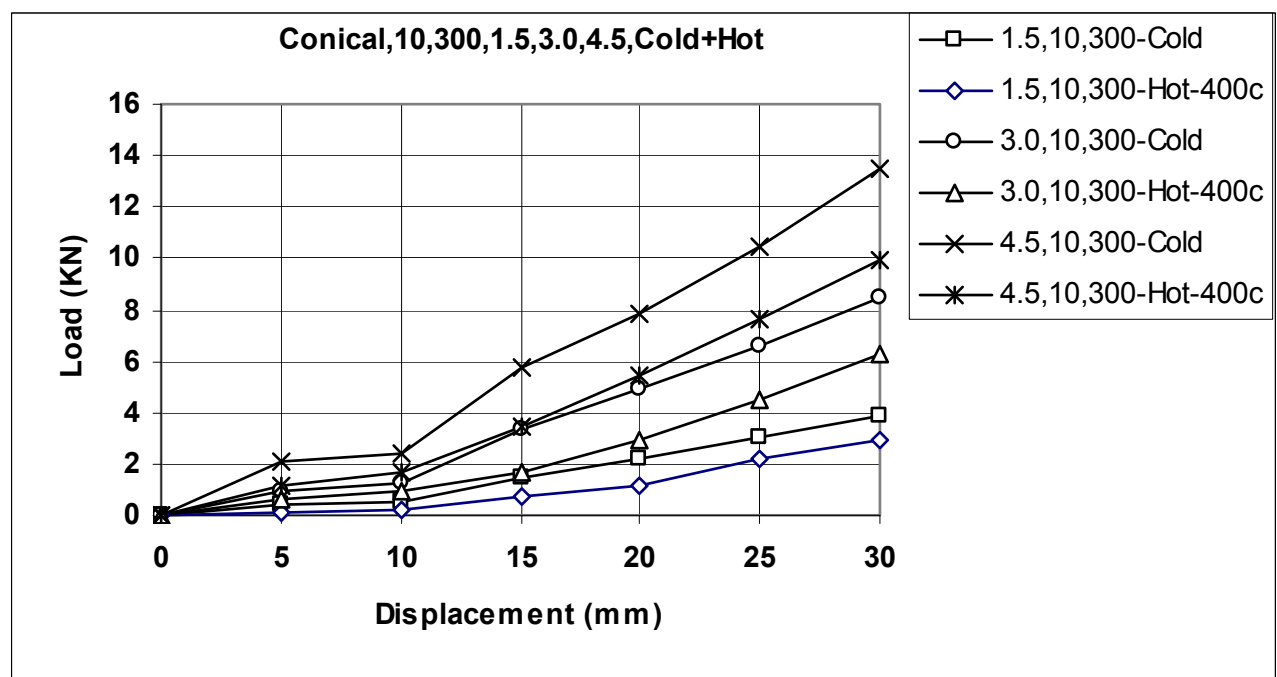

Figure 8. the load-displacement for both simulation and experimental work

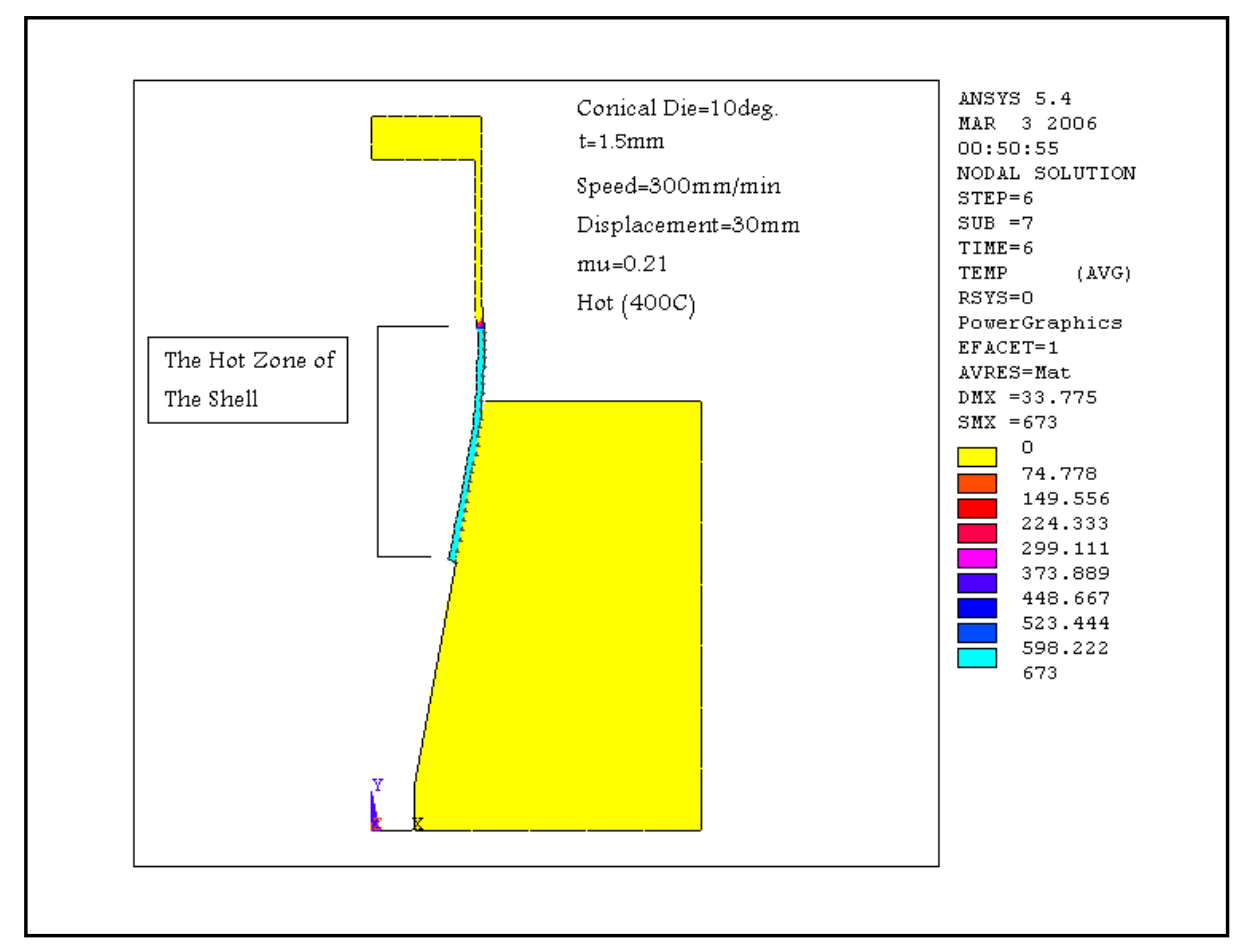

Figure 9. the figure of simulation for conical die (hot) 

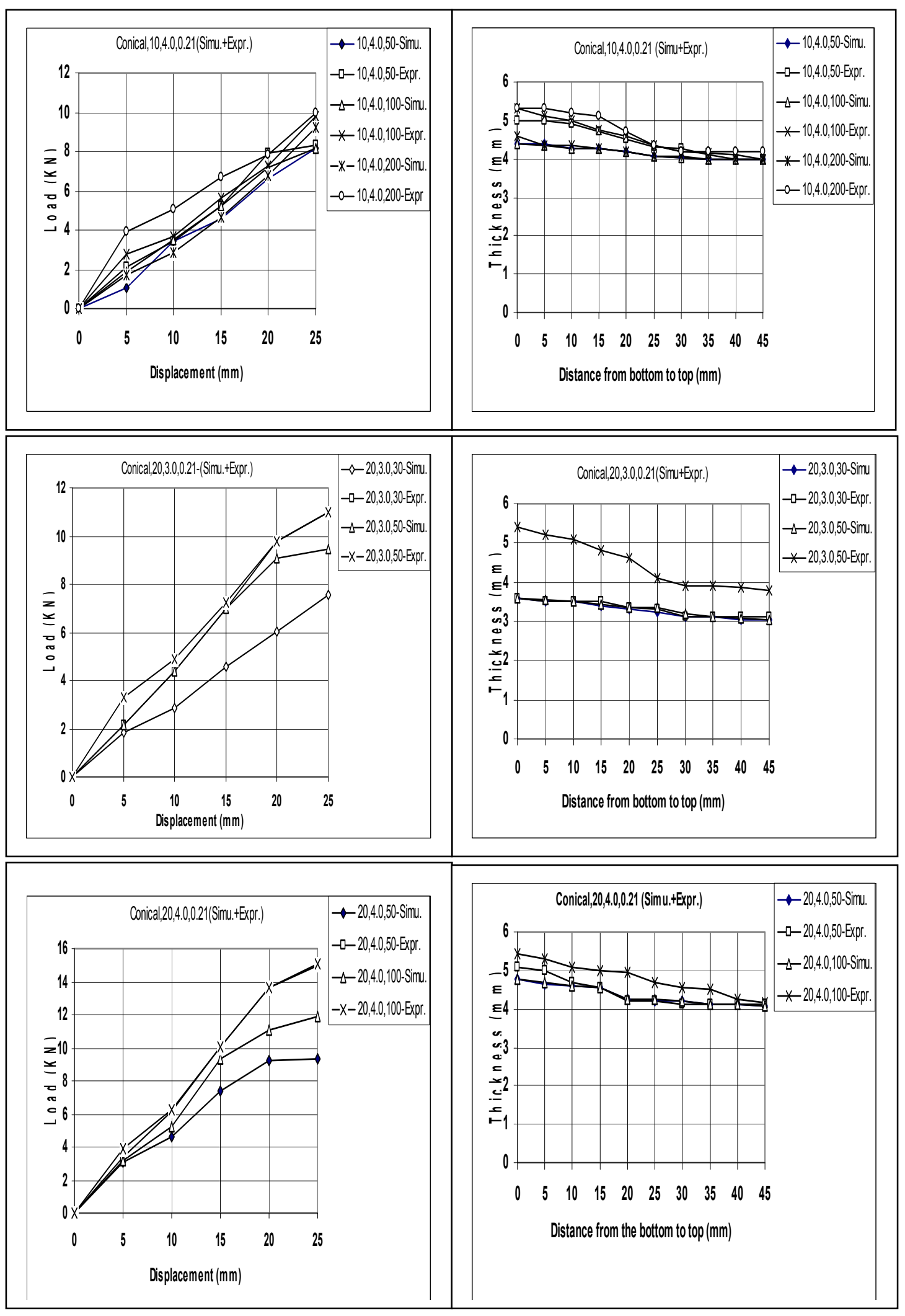

Figure 10. left- The load-displacement for simulation and experimental work

Figure 11. right-The thickness-distance for simulation and experimental work 

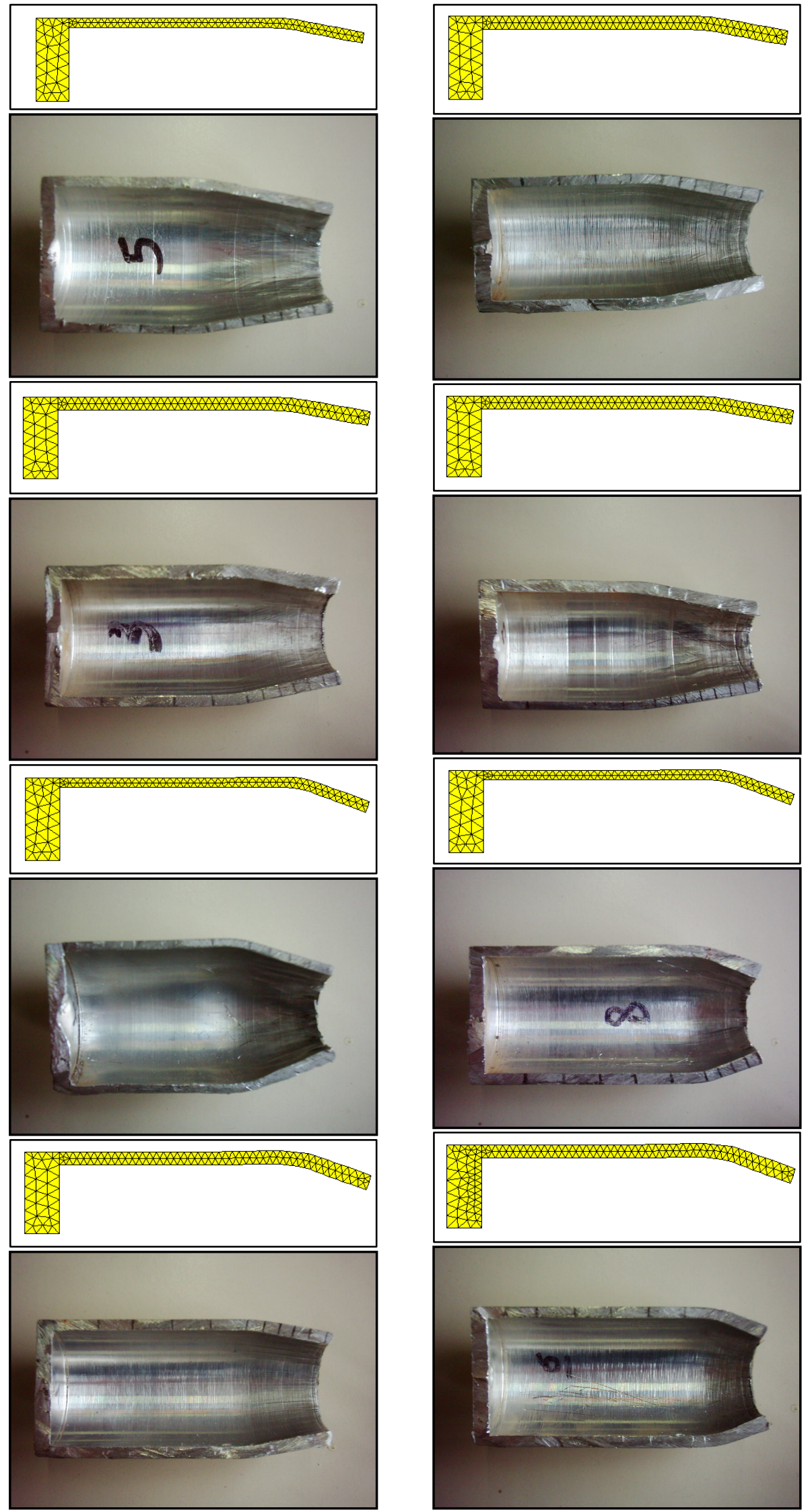

Figure 12. simulation and experimental work for $25 \mathrm{~mm}$ displacement 
a- $\mathrm{t}=3 \mathrm{~mm}, \mu=0.21$, angle $=10^{\circ}, \mathrm{v}=30 \mathrm{~mm} / \mathrm{min}$.

$\mathrm{b}-\mathrm{t}=4 \mathrm{~mm}, \mu=0.21$, angle $=10^{\circ}, \mathrm{v}=50 \mathrm{~mm} / \mathrm{min}$.

$\mathrm{c}-\mathrm{t}=4 \mathrm{~mm}, \mu=0.21$, angle $=10^{\circ}, \mathrm{v}=100 \mathrm{~mm} / \mathrm{min}$.

$\mathrm{d}-\mathrm{t}=4 \mathrm{~mm}, \mu=0.21$, angle $=10^{\circ}, \mathrm{v}=200 \mathrm{~mm} / \mathrm{min}$.

$\mathrm{e}-\mathrm{t}=3 \mathrm{~mm}, \mu=0.21$, angle $=20^{\circ}, \mathrm{v}=30 \mathrm{~mm} / \mathrm{min}$.

$\mathrm{f}-\mathrm{t}=3 \mathrm{~mm}, \mu=0.21$, angle $=20^{\circ}, \mathrm{v}=50 \mathrm{~mm} / \mathrm{min}$.

g- $\mathrm{t}=4 \mathrm{~mm}, \mu=0.21$, angle $=20^{\circ}, \mathrm{v}=50 \mathrm{~mm} / \mathrm{min}$.

$\mathrm{h}-\mathrm{t}=4 \mathrm{~mm}, \mu=0.21$, angle $=20^{\circ}, \mathrm{v}=100 \mathrm{~mm} / \mathrm{min}$. 